\title{
What We Know Now: Education, Neuroscience and Transdisciplinary Autism Research.
}

\author{
Jackie Ravet, Justin H G Williams
}

University of Aberdeen 


\title{
What We Know Now: Education, Neuroscience and Transdisciplinary Research in
}

\section{Autism.}

Jackie Ravet (corresponding author)

University of Aberdeen

Email: j.ravet@abdn.ac.uk

Justin H G Williams

University of Aberdeen

Email: justin.williams@abdn.ac.uk

\begin{abstract}
:
Background: Knowledge about the brain has been growing rapidly since the 1990s as a result of developments in neuroscientific research linked to improvements in functional neuroimaging and other brain imaging technologies. As the brain is the "principal organ involved in learning' (Diamond cited in Howard-Jones 2007 p1), it would seem reasonable to assume that education should be one of the chief beneficiaries of this research, leading to advances in our understanding of how people learn, the development of new curricula, and innovative teaching and learning approaches. However, the linkage between neuroscience and education has, historically, always been weak, and, we suggest, continues to be so, notwithstanding important research initiatives since the year 2000 .
\end{abstract}

Purpose: The purpose of this paper is to critically explore current theoretical understanding of joint neuroscientific and educational research, herein referred to as 'neuroeducational' research. There is a particular focus on a critique of the transdisciplinary model as applied in a study of imitation in learners with autism.

Main argument and sources of evidence: The review of the literature in the first half of the paper identifies the key barriers to neuroeducational research, including neuromyths, lack of 
shared understanding, the problem of the translation of neuroscientific findings to schools, and clashing research assumptions, methodologies and traditions. However, a model of transdisciplinarity is presented as a possible way forward. This model is tested in the second half of the paper against the experiences of the authors in conducting transdisciplinary research in autism and imitation in the secondary classroom. Here, we develop the concepts of 'transfer affordances', 'transfer challenges' and 'transfer opportunities' to structure our analysis of the various dimensions of the transdisciplinary research process. These new concepts are defined, and their relevance and utility explained.

Conclusions: The main conclusion of the paper is that the transdisciplinary research process within neuroeducation is complex, far from fully understood and requires further mapping. It is proposed that the concepts of 'transfer affordances', 'transfer challenges' and 'transfer opportunities' are useful theoretical ideas in pursuit of this aim.

Keywords: autism, education, neuroscience, neuroeducation, transdisciplinary research 


\section{What We Know Now: Education, Neuroscience and Transdisciplinary Research in} Autism.

\section{Background:}

In every phase of education, from early years to later life, there are educational issues whose understanding requires concepts about brain function. The debate about how this knowledge should be included in educational thinking has only just begun (HowardJones 2007 p4).

Neuroscience is defined as the study of the nervous system, principally the brain and spinal cord, and embraces a broad range of disciplines ranging from behavioural and cognitive studies of humans and other animals, through to molecular and cellular neuroscience. Around the new millennium, following advances in neurotechnology, there was a surge of interest amongst educationalists and educational researchers in the potential of neuroscientific research to transform our understanding of learning. It is, perhaps, surprising that up until this point few connections were ever made between the two fields - they existed, seemingly, in quite separate and distinct research worlds. The landmark review of neuroscientific research and its relevance for education by Blakemore and Frith (2000) was a notable attempt to question this separateness and to explore what synergies and applications education and neuroscience might offer each other. This call for more joint research was amplified by others and stimulated a number of international reviews and research initiatives (OECD 2002, Geake \& Cooper 2003, Goswami 2006, Howard-Jones 2007). A growing body of literature concerned with the intersectionalities between neuroscience and education has accumulated since, with the new interdisciplinary field variously referred to as learning science, eduscience, neuroeducation and eduneuroscience. For convenience, ${ }_{2}$ we adopt the term 'neuroeducation' throughout the remainder of this paper. Neuroeducation is defined as 'transdisciplinary collaboration between 
those working in education and neuroscience (to) assure optimal outcomes in terms of scientific validity and educational relevance' (Howard-Jones et al. 2015 p.228). Notably, it is not defined by methodology or output but as an activity between researchers coming from alternative theoretical perspectives.

\section{Education and Neuroscience: A Troubled Alliance}

Within the field of neuroeducation ${ }_{2}$ the case for closer collaboration between education and neuroscience rests upon the claim that it holds the potential to address the theory/practice gap (Donovan 2013, Glennon et al 2013) - i.e., the problematic connection between neuroscientific research findings relevant to education and their implementation in schools and classrooms. This is a problem that has beleaguered education for decades and was first mentioned by Dewey (1899 cited by Glennon et al. 2013). A number of fundamental propositions about the value of such a collaboration recur in the literature: that neuroscientific research is necessary to understand how and why learning occurs; that it can clarify individual differences in learning; that it will help shape educational curricula, approaches and practices; that it will open up new areas of educational research; that it could foster the development of a common language and understanding of learning across disciplines (Donovan 2013, Samuels 2009, Howard-Jones 2007, Blakemore, S.J. \& Frith, U. 2005). However, so far, the alliance of education and neuroscience has been fraught with difficulty.

There are a number of reasons for this. A key issue is that some education programmes currently in widespread use in schools purport to be 'brain-based' but have never been independently evaluated, are 'unscientific' in their approach and/or are unknown to neuroscience (OECD 2002, Goswami 2006). A prime example is 'brain-gym', a sequence of movement exercises claimed to have a direct influence on the brain to stimulate and enhance so-called ‘whole brain' learning (Dennison \& Dennison 1994). The Brain Gym exercise 
programme is purported to be based on scientific research relating to neurological repatterning, cerebral dominance and perceptual-motor training (Hyatt 2007). However, the evidence base for these theoretical notions has been repeatedly challenged, as have the claims about the exercises said to stimulate them (Hyatt 2007). Brain Gym was therefore rejected by leading neuroscientists as a 'neuromyth' early on in the debate about the value of neuroscience to education (Frith \& Blakemore 2000). The notion that there are fixed, 'critical periods' of learning, that learners have distinct 'learning styles' and 'multiple intelligences', and the idea that learners can benefit from instruction in 'left and right brain learning' have been similarly questioned (see, for example, Geake 2008, Howard-Jones 2010). However, this has not stopped neuromyth-based notions and related practices from flourishing in many U.K. classrooms, which has, to some degree, generated scepticism amongst neuroscience researchers and damaged the case for transdisciplinarity.

The proliferation of such neuromyths is possible, at least in part, because of the wholly understandable lack of neuroscientific literacy amongst education practitioners. The majority of teachers are simply not in a position to test the veracity of neuroscientific findings and identify dubious claims. This means that misunderstandings about the mind and brain are widespread. Indeed, in a study of 242 primary and secondary teachers from the UK and Netherlands and their perceptions of a range of neuromyths, it was found that the teachers believed half of the presented myths (Dekker et al. 2012). This has led to widespread calls for improved scientific literacy amongst teachers (Dekker et al. 2012) so that they have the skills to critically evaluate scientific claims before incorporating them into their practice.

Daniel (2012) warns that even in cases where the claims of brain science are replicated and widely supported, scientific findings emerging from the controlled conditions of the laboratory do not necessarily or readily translate to the far more complex, situated and interactive context of the classroom. Such contexts can transform behaviour and learning, rendering laboratory 
findings obsolete. There are therefore dangers in simply transferring 'good' science to the classroom; the so called 'brain scan to lesson plan approach' (Howard-Jones et al. 2015). Thus, it is argued that as well as training, greater dialogue between the two disciplines is necessary to both initiate knowledge transfer and exchange and to bridge the gap between scientific research and classroom application (Howard-Jones et al. 2015). On the surface at least, this joint 'neuroeducational' approach seems most likely to assure theoretically sound and effective outcomes (Howard-Jones et al. 2015). For example, Hill et al. (2010) drew on laboratory-based and cognitive neuroscience to enable practising teachers to design and implement a carefully controlled, exercise-based intervention delivered in a classroom setting by teachers that generated measureable benefits upon attentional abilities. The intervention was grounded in sound theoretical rationale and the outcome measures were robust, whilst the methods could be easily applied widely in any educational setting.

However, Samuels (2009) advises that the process of neuroeducational research can be problematic as a result of the differing histories and the opposing epistemological, ontological and methodological assumptions that underpin the quantitative, scientific research tradition associated with neuroscience, and the qualitative, interpretative research tradition that has often been associated with educational research. The two traditions appear to stand in sharp contrast to each other. Indeed, over the years, proponents of both approaches have claimed the preeminence of their paradigm and have stressed the incompatibility of the two approaches, resulting in the 'paradigm wars' (Guba 1990, Maxwell \& Delaney 2004). Traditionally, in Western cultures, the so-called 'hard' sciences have been highly valued for their presumed objectivity and generalisability and awarded high status. By contrast, qualitative research, referred to by some as a 'soft' science, has traditionally been conferred lower status due to its subjective and situated nature. It is apparent that these cultural values persist today (see Harsh 2013). 
However, the past decade has seen the emergence of a 'third paradigm' that, arguably, resolves the perceived opposition between quantitative and qualitative research. Advocates propose 'mixed methods' research (Creswell 2003, Tashakkori \& Teddlie 2003) that combines quantitative and qualitative designs in order to address social phenomena alongside material phenomena within a framework based on ontological and epistemological 'pluralism' (Burke Johnson \& Onwuegbuzie 2004). This ‘compatibilist' position (Burke Johnson \& Onwuegbuzie 2004) has heralded the rise of joint research, variously referred to as multidisciplinary (two or more disciplines working alongside each other), interdisciplinary (two or more discipline collaborating together) or transdisciplinary (the fusion of two or more disciplines to create a new discipline) (Della Chiesta et al. 2009). The growing currency of mixed methods research in the U.K. is reflected in the fact that interdisciplinarity is increasingly promoted in Higher Education establishments and is rewarded via the Research Evaluation Framework (REF) which assesses research excellence. These developments are good news for the future of neuroeducational research.

Samuels (2009), however, warns that, though neuroscientific and educational research approaches may now be considered compatible, joint working could still be problematic. For example, she suggests that it is unrealistic to expect educational practitioners to become conversant with complex neuroscientific theories, or indeed, to expect neuroscientists to become conversant with educational theory. She therefore advocates that researchers recognise their philosophical, epistemological and methodological differences but focus on capitalising upon their unique strengths. She recommends a 'transdisciplinary' rather than a multidisciplinary or interdisciplinary model of neuroeducation:

'Transdisciplinarity is an approach to examining and solving complex problems through the collaborative efforts of multiple diverse partners. It recognises that knowledge is inherently something that is constituted at the level of the group and the 
activity rather than each individual participant... What connects transdisciplinary participants is not a common theoretical perspective or methodology or epistemology, but a common issue to which all apply their own particular expertise with the goal of reaching a holistic understanding of the issue' (p49)

Samuels claims that transdisciplinarity is distinctive in that it leads to 'transcendence' - a situation where no single discipline assumes dominance in order to allow for mutual integration from which new insights can emerge. Mutuality and equality are therefore the hallmark of transdisciplinary research ${ }_{2}$ in her view. These qualities are important since, to date, much collaboration between education and neuroscience has been highly unequal, with education very much in a minor support role (Samuels 2009). The outcome is that the barriers to the implementation of neuroscientific findings in schools continue to be under-researched and remain invisible. Another consequence is that neuroscience researchers may find it difficult to develop an understanding of the 'procedural knowledge' required to undertake research in schools (Plummer et al. 2014). However, Samuels' notion of 'transcendence' is vague, and it is unclear how, exactly, the mutuality and equality she speaks of can be established. We will return to this matter in the second half of the paper.

The recent rise in the popularity of mixed methods research has, arguably, created an enabling climate for transdisciplinary neuroeducational research. It is towards this emerging space that autism researchers are beginning to turn; a turn that has been provoked by recent research providing evidence of a significant disjunction between neuroscientific autism research and applied social and educational autism research (Dunlop, et al. 2016). For example, a U.K. study by Pellicano et al. (2013) showed how autism research is still dominated by large scale positivist studies focusing on causation, brain research and underlying biological factors; especially randomised control studies (RCTs). This research attracts $56 \%$ of UK funding for autism research (Pellicano et al. 2013). By contrast, smaller scale applied research that focuses 
on the efficacy of treatments and interventions are underrepresented and underfunded. This research attracts only $18 \%$ of UK funding for autism research (Pellicano et al. 2013). The research also highlights the fact that new educational interventions for learners with autism are rarely underpinned by neuroscientific autism research. Few studies explore how individuals with autism think and learn in schools (Pellicano et al. 2014).

As a corollary, there are growing calls, from within the autism community and beyond, for more research to bridge the gap between neuroscientific theory and autism practice ${ }_{2}$ in order to improve educational impact and help to change the everyday lives of people with autism (Pellicano et al. 2013). Autism research is therefore a site of considerable potential for neuroeducational transdisciplinary studies. In the next section of the paper, we will critically explore this potential as it relates to a neuroeducational study of imitation skills amongst secondary school pupils with autism.

\section{A Neuroeducational Study: Imitation in Autism}

\section{Research Background}

Autism is defined as a lifelong, neurodevelopmental disability of biological origin that is diagnosed with reference to a dyad of impairments (Ravet 2015). The first element of the dyad refers to problems with social communication and social understanding; the second element refers to problems with flexibility of thought and sensorimotor function. Since autism is a spectrum condition, the behavioural manifestations of autism arising from the dyad of impairments are complex and multifaceted. However, a key characteristic is difficulties in expressing emotional states using non-verbal behaviours such as gesture, facial expression, eye-contact and other non-verbal socially communicative behaviours. Individuals with autism are also challenged by the non-verbal communications of others (Ravet 2015). Such problems can have profound negative consequences for people with autism with respect to relationship 
formation, social functioning and learning in general. They are also associated with stress, anxiety and behaviour that can be challenging for individuals with autism as well as their families, carers and the professionals who support them (Ravet 2015).

Research suggests that many teachers still lack an understanding of autism and find it difficult, amongst other things, to support the social and emotional development of this group of pupils (Eman and Farrell 2009). Teachers will therefore benefit from a greater understanding of this aspect of autism. They require approaches and interventions that enable them to support learners with autism to improve social communication abilities in order to enhance wellbeing and increase inclusion, participation and learning in the classroom and in everyday life.

Over the past two decades, autism research has generated a plethora of findings to explain problems with emotional communication in autism. This is not the place for a comprehensive review of this research but some key themes will be identified. At the psychological level, a wealth of research has demonstrated that people with autism have problems with the ability to understand, reflect on and be aware of their own mental states, and those of others, referred to as weak 'theory of mind' (Baron-Cohen et al. 2000). These are summarised as problems with empathy which can be reliably rated through the use of questionnaires experimental tasks (Baron-Cohen \& Wheelwright 2004, Baron-Cohen et al. 2001, Spreng et al. 2009). However, the way that these problems develop is open to much debate. Neuroscientific research has highlighted the potential importance of the orbitofrontal-amygdala network which underpins emotional learning (Dawson, Webb \& McPartland 2005), whilst other work has focussed on medial frontal cortex and the temporo-parietal junction which have been associated with the cognitive capacity to form representations of mental states (Saxe 2006). Differences in the anatomy and function of both systems have been demonstrated in individuals with autism compared to neurotypical individuals, as well as differences in patterns of brain connectivity 
within and between these systems. Other work has pointed to problems with executive function, particularly 'planning' (Ozonoff et al. 2004).

Meanwhile, however, within psychology, fundamental changes in thinking have given rise to theories of embodied cognition (e.g. Niedenthal et al. 2006, Barsalou 2008). This reflects a move away from Cartesian models where cognitive processes are seen as being separate from the sensory and motoric functions which communicate with them, as well as modular processes which ascribe specific cognitive functions to discrete brain regions. Within the embodied cognition perspective, the cognitive processes that serve empathy are considered to be fundamentally grounded in the sensory and motoric mechanisms which serve their perception and enactment. Empathy is considered to rely on "simulation", whereby one understands another person's thinking by imagining ones' self , so to speak, 'in the other person's shoes'. It may be described as "off-line imitation" as one imitates without actually moving any body parts. Empathy is therefore intimately linked to the perception, memory and enactment of action, and relies on those brain mechanisms which serve perception, imagery and enactment of socially communicative actions (Gordon 1996, Gallese \& Goldman 1998). Developmental theories place imitation at the centre of this developmental cascade.

However, whilst problems with imitation have been robustly and closely associated with autism (Edwards 2014), the brain mechanism that underpins these problems still awaits clarification. So far, studies of the capacities to perceive action and emotion fail to reveal significant differences between the workings of typical brains and autistic brains, as do studies of simple goal-directed actions. Williams (2001, 2004, in press) considers that problems with affective learning mechanisms for action, dependent upon linkage between medial frontal cortex and orbito-amygdala systems, could provide a unifying explanation for the deficits in executive function, imitation and simulation-based empathy that occur in autism. Problems within this mechanism mean that the typical developmental process by which children with autism learn 
to ascribe appropriate affective values and meanings to the actions of others fails to occur. Consequently, problems emerge with learning those behaviours (through imitation) which are culturally appropriate for the expression of emotion, as well as learning to associate others' action-patterns within specific emotional contexts, giving rise to a broad array of socioemotional difficulties.

This work begs further questions:

- is it possible to ameliorate these difficulties in imitation?

- can imitation skills be enhanced? If so, how?

- what might be the implications of such a study for our understanding of imitation and social learning?

- will improved imitation skills generalise to improve social functioning?

These are the research questions at the heart of a neuroeducational research study which has arisen from Williams's work. In order to address the questions, a collaborative research group was assembled, including two clinical researchers, an educational researcher and a drama specialist. Note that one of the clinical researchers and the educational researcher in the group were the principal investigators and the authors of this paper. For all of us, this was our first experience of working together in this group in this way.

The aim of the group was to create an educational drama programme that would translate the neuroscientific findings on imitation into a practical educational intervention. In a pilot study conducted in 2014, this drama programme was introduced to a small group of four secondary students with autism (S1-S3) in a secondary classroom over six, 45 minute drama lessons. The programme was led by the educational researcher and drama specialist, and informed consent, institutional approval and ethical approval were granted prior to commencement. The researched used mixed methods. Quantitative measures administered before and after the 
programme included the Social Skills and Social Competence Questionnaires (Spence, 1995) given to all pupils, teachers and parents, and two on-line tests for pupils only; Perception of Emotion Expression (Braadbaart et al. 2014) and Imitation of Facial Expressions (Williams et al. 2013). Qualitative measures consisted of structured observations of pupils during the study and interviews of pupils, parents and teachers pre- and post- programme.

Details of this pilot study are explored in a separate paper (Ravet \& Williams forthcoming). Our interest, here, lies in the experience of the joint research as encountered by the two principal investigators in the study (the authors of this paper), focusing on a critique of the challenges raised during the knowledge transfer process.

These challenges are conceptualised as 'transfer barriers' in the neuroeducation literature since they complicate and undermine knowledge exchange across disciplines (Della Chiesa 2009). However, we would challenge this term on two fronts. Firstly, we suggest that many of these so-called barriers are only perceived and do not actually exist. Laboratory neuroscience and education represent two extreme ends of a landscape of disciplines concerned with child development and learning. Clinical psychology and psychiatry sit somewhere in the middle and are familiar with the challenges presented from both sides. Arguably, it is the distance between the two disciplines that obscures their commonalities, creating the perception that their problems are entirely unique. Secondly, the term 'barrier' is loaded with negative connotations and hardly seems a positive way to take forward a transdisciplinary endeavour, when the object should be to share expertise and for each side to welcome the innovations the other discipline can offer. We therefore propose that the word 'barrier' is a misnomer and that it might be more helpful, and more in keeping with the spirit of transdisciplinarity, to refer instead to 'transfer challenges' and 'transfer opportunities'. 
We define transfer challenges as the difficulties arising from the process of joint neuroeducational research that block effective knowledge exchange; transfer opportunities are the possibilities for joint development these challenges might generate if seized upon positively. The progression from challenge to opportunity is vital within this conception, as it is the step that holds transformative potential. Similarly, we use the term 'transfer affordances' to refer to the benefits that accrue from the knowledge exchange process. All three are examined below.

\section{Transfer Affordances}

\section{Innovation and Operationalisation}

In line with other neuroeducational researchers (e.g. Varma 2008, Della Cheasa et al. 2009) we found that a major affordance of joint research is the knowledge transfer and exchange that it both necessitates and facilitates, and the gains that accrue for all parties as a result. Many indepth discussions took place between the two authors of this paper during the development of the neuroeducational research project in order to share and clarify the complex autism neuroscience underpinning the research on the one hand, and the learning and teaching context in which the empirical study was to take place on the other. By bringing this knowledge and expertise together, it was possible to bridge the gap between the objectives determined by the cognitive science and the requirements to achieve learning in a classroom setting.

We jointly constructed a highly innovative educational drama programme to explore whether secondary school pupils with autism can explicitly learn imitation and empathy skills relating to emotions, and whether this leads to some amelioration of autistic difficulties and some enhancement of social skills. The partnership meant that there was no need for the educationalist to attempt to evaluate and translate neuroscientific theory, as this expertise was available within the group. Theoretical misunderstandings and neuromyths could therefore be 
avoided. Equally, it was vital for the neuroscientist to gain some understanding of the educational issues and contextual factors that would have to be negotiated during the empirical phase of the study. Indeed, the translation of Williams' work into a form appropriate for, and relevant to, the classroom, and to pupils learning in those classrooms, is absolutely key to the success of the research study. Research expertise was therefore viewed as capital, and was freely exchanged and highly valued.

\section{Methodological Rigour}

The pooling of methodological perspectives from neuroscience and education was also essential to the development of a coherent research design. The choice of a 'pragmatist' methodological framework enabled the team to adopt a practical problem-solving approach to the 'real world' educational issues arising from imitation difficulties (Feilzer 2010). This framework is compatible with the transdisciplinary 'issues-based' model advocated by Samuels (2009) in which researchers from diverse backgrounds come together to apply their expertise to 'a common issue' in order to 'reach a holistic understanding' (p49). The methods used in the study draw equally from the quantitative and qualitative research traditions; the former involving surveys and on-line perception and imitation tests yielding statistical data; the latter drawing on structured observation of the intervention in the classroom, and on focus groups and interviews with pupils, parents and teachers. The result is a transdisciplinary research design that is effectively triangulated and methodologically rigorous. This design was successfully operationalised during the pilot study (see Ravet \& Williams Forthcoming), confirming, provisionally at least, that linking neuroscientific theory to educational practice in the field of autism has potential. The results of the pilot study also yielded a tantalizing, though conditional, affirmative to the strategic question of whether emotional imitation can be taught. 
This potential will be explored more fully in the forthcoming wider implementation of the imitation study.

\section{Knowledge Transfer and Advancement}

Another affordance of our neuroeducational approach is that it was possible to present jointly our research proposal and rationale at a high profile international educational research conference in front of peers with a special interest in neuroeducation but a non-specialist neuroscientific background. This is significant, as it required further joint collaboration to successfully communicate complex neuroscientific ideas and connect information across disciplines in a manner that was meaningful for the audience. This is an example of effective knowledge transfer beyond the small research group and is a hallmark of transdisciplinarity (Schwartz 2015). Arguably, there is an ethical imperative behind communication at this level, as interdisciplinary research must be open to peer scrutiny in the same way as unidisciplinary research (Howard-Jones and Fenton 2012). Dialogue between neuroscientists and the education community also reduces the possibility of misunderstandings resulting in neuromyths, and, hopefully, establishes a powerful case for neuroeducation. However, according to Della Chiesa et al. (2009) this is an area of significant weakness in joint research teams, many of whom do not appreciate the importance of communicating widely across fields in order to extend the reach and influence of neuroeducation and to inspire further 'innovation and advancement '(Della Chiesa et al. 2009).

\section{Transfer Challenges}

Despite the considerable strengths and benefits of the transdisciplinary model in facilitating the development and operationalisation of the imitation pilot study, the experience was not always a straightforward one and did not, in certain respects, fulfil the criteria for transdisciplinarity as defined by Samuels (2009). Indeed, aspects of the 'mutual exchange' that Samuels 
emphasises have been challenging. Under this heading, we do not directly consider the many logistic constraints that will inevitably arise in research teams, such as differences in capacity, or the structural barriers that are commonly experienced, such as lack of time, professional workloads, etc. Rather, we focus only on those differences we regard as specifically pertinent to neuroeducational transdisciplinary research in the hope of making some useful contribution to the development of the field.

\section{Reliance on Specialisms}

It is clear, on refection, that a key characteristic of the research partnership established for the joint imitation study was our tendency to remain within our specialisms. Indeed, we utilised, and relied on, each other's expertise in a largely unquestioning way. We failed to create opportunities for joint training or even for informal critical discussions where we might have challenged each other and raised important epistemological and ontological questions. Opportunities were also lost to 'swap hats' (Sheridan et al. 2006 in Howard-Jones and Fenton 2012) and explore each other's disciplinary domains. Thus, the clinicians did not participate in, or even observe, the teaching and learning conducted in the classroom during the study. Likewise, the educationalists did not participate in facilitating the on-line neuroscientific tests used with the pupil participants, or the analysis of the results. This was left entirely to the 'experts'. Though 'swapping hats' has its limitations and can, potentially, raise challenging ethical issues (Sheridan et al. 2006 in Howard-Jones and Fenton 2012), we see this now as an opportunity missed.

Whilst this lack of epistemic sharing did not in any way undermine our key research purposes, it prevented us from developing a deep and secure level of mutual understanding and from developing new knowledge synergistically (Della Chiesa et al. 2009). The collaboration was 
therefore narrow and superficial at an epistemic level with the team working together to 'get things done' (Head 2003) rather than to nurture a deeper 'knowledge-building community' (Scardamalia \& Bereiter 2003) and 'community of practice' (Wenger 1998). On the basis of our experience we would therefore agree with the literature presented in the first half of this paper that advocates joint training, and would disagree with Samuels' (2009) claim that joint training and a common perspective are unnecessary and unrealistic goals. With hindsight, our lack of training did not serve us.

\section{Working Practices and Contexts}

As a consequence of our reliance on specialisms, important differences in working practices and contexts were not sufficiently explored prior to entry into the field. For example, as a clinical neuroscientist, Williams originally conceived of the autism and drama intervention as an Empirically Supported Therapy (EST). He envisaged a manualised intervention delivered like a psychotherapy but in the environment of the classroom instead of the clinic, with quantifiable outcomes and clearly defined variables. The aim was to develop a model of intervention that could be delivered in a standardised way in a randomised controlled trial. In presenting this to the educationalists, it was proposed that this design could be transferred directly to a classroom context. This turned out to be highly problematic.

Firstly, by their very nature, specialist clinics are very different contexts from classrooms. They provide a hub for patients with a common set of difficulties that leads to them being concentrated in one place in large numbers. This makes it feasible to develop and administer 'treatments' and examine efficacy with the use of quantitative methods to measure outcomes, particularly short-term outcomes. However, by seeking to transfer such an approach to the naturalistic setting of the classroom, the first problem is that the client group are already 
dispersed. In line with this dispersal, given the heterogeneity of most clinical problems, when potential participants in the intervention are co-located, they are likely to have markedly different needs. This is very much the case with autism. Our intervention was designed to be administered to a group, requiring a number of young people with similar levels of ability to be co-located in a single setting. Even with the increased recognition and prevalence of autism as it is recognised today, finding a sufficiently large group of voluntarily consenting participants with comparable autistic impairment co-located in a single school, proved challenging. Therefore, the first difference between education and clinical application arose simply as a result of the differential co-location of potential participants. This delayed the start of the study and led to doubts about the feasibility of using an education setting as the context for the study.

\section{Perceptions of Autism}

To add to this there were differences, largely unaddressed, in the way that autism is conceived in clinical practice compared with education. Autism was originally described by a child psychiatrist and seen as a psychiatric 'disorder', requiring management in clinics and hospitals. Over the years the diagnosis has broadened. The importance of management in education has been increasingly acknowledged and autism education has become a specialist field in its own right. Importantly, though, the objectives of teachers and clinicians may be very different, as well as the language they use to discuss autism.

This was very much the case within the research group. For example, the author who is a clinician was interested in looking for short-term gains in clinically measurable variables, termed 'symptoms', by administering 'treatments'. He drew predominantly on a medical model of autism and categorised it as a 'disorder'. By contrast, the educationalist was concerned with addressing individual needs or 'differences' via tailored interactions between teachers and 
pupils and by making adjustments to the learning environment, termed 'interventions'. She drew largely on a social model of autism and categorised it as a 'condition'.

In our study, we thought we could simply sidestep the complexity arising from these differences by addressing both agendas and collecting data on all outcomes. In the end this proved overly demanding on time and resources which, in turn, necessitated difficult discussions about reducing data collection, data analysis, time spent in schools and money spent on transcriptions and other forms of research support. For example, from the clinical point of view, interviews with parents and teachers were considered relatively superfluous since the key clinical focus was on the quantitative measurement of individual pupil symptoms over time. A case was therefore made to save time and resources by cutting them from the study. However, for the educationalist, teacher and parental perspectives were vital in order to establish whether, and how, context influenced imitation behaviour, and to triangulate the qualitative data captured in pupil interviews. A strong case was therefore made for them to be retained, despite the costs. Arguably, such disputes may have been avoided if there were a more concerted effort, in the early stages of the pilot study, to transfer knowledge and critically explore epistemic differences with the aim of achieving a clearer, shared understanding of the research process.

\section{Differing Values}

In seeking to make sense of the tensions outlined above, it seems clear to us now that part of our reluctance to critically explore our specialisms, our working practices and our perceptions of autism may have related to underpinning values. Values, by their very nature, define us as human beings and are fundamental building blocks of individual and professional identity. The matters that confronted us touched on our most deeply held ontological and epistemological 
assumptions and challenged our foundational beliefs. Our tendency was therefore to protect and defend these identities; we found that they were not easily 'transcended' as Samuels (2009) advocates. So here, the transdisciplinary model came unstuck and the 'mutuality' and 'equality' that Samuels emphasises failed to emerge. Though better training in the epistemic traditions of education and neuroscience may have helped in this respect (Schwartz 2015), it seems clear that deeply felt beliefs cannot simply be 'trained', but evolve through a more obscure human process that is difficult to theorise and plan for. Samuels does not explore this in her analysis of transdisciplinarity; it is as if mutuality and equality are inevitable by-products of respectful and committed joint working. We would suggest that this is not necessarily the case. It seems to us, now, that mutuality and trust require safety within the partnership that can only be established by working through disagreements that inevitably occur during the course of a long term joint research commitment. This calls for interrelational openness and honesty, and much trial and error. This process is far 'messier' than the idealised theoretical models set out in the neuroeducation literature. Indeed, it is one that we are coming to grips with only now, as we reflect back on our experiences.

\section{Transfer Opportunities}

Schwartz 2015 notes that the collaboration between neuroscience and education is 'a difficult process to maintain and develop' (p67). The discussion above has explored some of these difficulties as they emerged from a neuroeducational pilot study in the field of autism research. Though the transfer affordances and challenges discussed are specific to the autism imitation research under consideration, it is hoped that they will resonate with the experiences of other transdisciplinary researchers in education and contribute to the ongoing debate on neuroeducation. 
What has emerged most powerfully from our experience is that transdisciplinarity in the field of neuroeducation provides a helpful, though idealised, model of joint research. We require a more detailed, realistic, map of how it might be conducted. For example, in Samuel's (2009) transdisciplinary model, a capacity to 'transcend' differences and capitalise on them is purported to be a strength, indeed, an aspiration, though the notion of transcendence is not explained. During the imitation pilot study, we found that this transcendence is not achieved by simply accepting differences and putting them aside. On the contrary, unattended differences began to assert themselves in unhelpful ways. This outcome is by no means unique, as the literature confirms (e.g. Varma et al. 2008, Della Chiesa et al. 2009).

In the light of such difficulties, Schwartz (2015) proposes a radical way forward. He suggests that for neuroeducational research to thrive we need 'research schools' led by a 'new generations of neuroeducators'. These neuroeducators are conceived of as researchers who are specifically trained to understand the complexities of the intersectionalities between education and neuroscience and to facilitate interactions between researchers, practitioners and other relevant parties (Schwartz 2015). Whilst this sounds tempting on paper, and would seem to address the need for the fusion of knowledge and skills that proved difficult to establish in the autism research partnership, in reality the development of research schools and neuroeducators will require funding, resourcing and a considerable investment of time and energy. There may be resistance from educationalists, parents and pupils to such an initiative, and questions will be raised about the social, cultural and ethical implications. Finally, it may be over-optimistic to expect one individual to develop such a panoply of skills ranging from interview techniques through to understanding of laboratory science and quantitative data analysis. There is therefore, we suggest, a long road to travel before such research schools are commonplace.

In the meantime, in order to support the future development of joint neuroeducational research, we suggest that it will be helpful for transdisciplinary researchers, as it has been for us, to 
explicitly, collaboratively and constructively explore the challenges faced during the research process with a view to identifying the transfer opportunities they might yield. This conception of 'transfer opportunities' enables a more positive and hopeful orientation towards the inevitable frustrations of transdisciplinary working, and has the potential to lead to more meaningful outcomes, both at an individual and group level. Three key transfer opportunities have been identified.

Firstly, we propose that transdisciplinary research provides an exciting opportunity for research teams to undertake early joint training, both formal and informal, aimed at explicitly identifying and addressing epistemic, procedural and values-based differences. This will enable such differences to be explicitly negotiated (rather than 'transcended') via a conscious, structured process (rather than mere avoidance) and is more likely to generate a shared understanding, a synthesis of ideas, a common language, and trust.

Secondly, it is also important to develop a shared understanding of the meaning of 'transdisciplinarity' and its associated characteristics so that 'mutuality' and 'equality' can be specifically prioritised, addressed and planned for. To this end, we strongly suggest that transdisciplinary teams should aim to 'swap hats', where appropriate. This will enable individual members to achieve a deeper insight into partner disciplines and the procedural processes associated with them, and thereby bring the highly theoretical concepts of mutuality and equality to life. The pilot phase of the study could be a useful 'test-bed' for this, providing an opportunity for critical reflection upon joint working as well as the methodological and operational matters that are the more traditional foci at this stage of a study. This may help to surface underlying problems early on in the research cycle, and enable a more informed and constructive transition into the next phase of the research process. 
Finally, and above all, attention should be paid to the quality of the collaborative partnership and involve explicit focus on enhancing the team's capacity for interrelational honesty, openness and conflict resolution, whilst appreciating that these qualities and skills evolve slowly over time. Team-building may therefore have an important role to play throughout the research process, and will require extra time and resources. For this reason, transdisciplinary research may take longer than unidisciplinary research. The interrelational aspects musts be built into research time-lines from the start if they are to be given the attention they deserve.

\section{Conclusions}

Autism researchers and other educational researchers are only just beginning to explore the potential of a transdisciplinary approach, so there is much to learn from the accumulating studies and evidence base emerging from the wider neuroeducation literature. We must build on this base to develop more neuroeducational studies that can effectively bridge the gap between the laboratory and the classroom in order to enhance our understanding of how brain function and learning are linked, and how these linkages might inform the development of new curricula and teaching approaches. This rich vein, as yet barely tapped, has the potential to enhance the educational experiences, attainment and achievement of all learners.

However, in order to achieve this, transdisciplinary studies require a higher profile. There must be a stronger commitment to transdisciplinary educational research from policy makers and funding bodies, allied with a greater awareness of the interrelational dimensions outlined above, and the approaches required to ensure success. The future of transdisciplinary neuroeducational research very much depends on this. 


\section{References:}

Baron-Cohen S, Tager-Flusberg H, Cohen DJ. (2000) ( $2^{\text {nd }}$ ed) Understanding other minds perspectives from developmental cognitive neuroscience, Oxford: Oxford University Press.

Baron-Cohen S, Wheelwright S. (2004) The empathy quotient: An investigation of adults with asperger syndrome or high functioning autism, and normal sex differences. Journal of Autism \& Developmental Disorders, 34(2):163-175.

Baron-Cohen S, Wheelwright S, Hill J, Raste Y, Plumb I. (2001) The "reading the mind in the eyes" test revised version: A study with normal adults, and adults with asperger syndrome or high-functioning autism. Journal of Child Psychology \& Psychiatry, 42(2):241-251.

Barsalou L.W. (2008) Grounded Cognition. Annual Review of Psychology, 59:617-645.

Blakemore, S.J. \& Frith, U. (2000) Report on the implications of recent developments in neuroscience for research on teaching and learning, London: Institute of Cognitive Neuroscience.

Braadbaart, L., de Grauw, H., Perrett, DI., Waiter, GD. \& Williams, JHG. (2014). The shared neural basis of empathy and facial imitation accuracy. Neuroimage, vol 84, pp. 367-375.

Burke Johnson, R. \& Onwuegbuzie, A. J. (2004) Mixed Methods Research: A Research Paradigm Whose Time Has Come, Educational Researcher, 33/7, 14-26.

Creswell, J.W. (2003) Research Design: Qualitative, quantitative and mixed approaches, Thousand Oaks, CA: Sage.

Daniel, D, B. (2012) Promising principles: Translating the science of learning to educational practice, Journal of Applied Research in Memory and Cognition, 1, 251-253.

Dawson G, Webb S.J. \& McPartland J. (2005) Understanding the nature of face processing impairment in autism: Insights from behavioral and electrophysiological studies.

Developmental Neuropsychology, 27(3):403-424.

Dekker, S., Lee, N.C., Howard-Jones, P. \& Jolles, J. (2012) Neuromyths in education: Prevalence and predictors of misconceptions among teachers, Frontiers of Psychology 3, 1-8

Della Chiesa, B., Christoph, V. \& Hinton, C. (2009) How Many Brains Does It Take to Build a New Light: Knowledge Management Challenges of a Transdisciplinary Project, Mind, Brain \& Education, 3/1, 17-26.

Dennison, P. E., \& Dennison, G. E. (1994) Brain Gym ${ }^{\circledR}$ teacher's edition--Revised. Ventura, CA: Edu-Kinesthetics.

Donovan, M.S. (2013) Generating Improvement Through Research and Development in Education Systems, Science, 340/6130, 317-319.

Dunlop, W-A, McGregor, E., Marwick, H., Ravet, J., Robinson, A., Rydzewska, E., Somerville, A. \& Stanfield, A. (2016) Action on Autism Research in Scotland: Report, Glasgow: University of Strathclyde. 
Edwards LA. (2014) A meta-analysis of imitation abilities in individuals with autism spectrum disorders. Autism Research, 7(3):363-380.

Emam, M.M. \& Farrell, P. (2009) Tensions experienced by teachers and their views of support for pupils with autism spectrum disorders in mainstream schools, European Journal of Special Needs Education, 24/4, 407-422.

Feilzer, M.Y. (2010) Doing mixed methods research pragmatically: Implications for rediscovery of pragmatism as a research paradigm, Journal of Mixed Methods Research, 4/1, 6-16.

Gallese V, Goldman A. (1998) Mirror neurons and the simulation theory of mind-reading. Trends in Cognitive Science, 2:493-501.

Geake, J.G. \& Cooper, P.W. (2003) Implications of Cognitive Neuroscience for Education, Westminster Studies in Education 26/10, 7-20.

Geake, J. (2008) Neuromythologies in Education, Educational Research 50/2, 123-133.

Glennon, C., Hinton, H., Callahan, T. \& Fischer, K.W. (2013) School-Based Research, Mind, Brain and Education, 7/1, 30-34.

Gordon RM. (1996) 'Radical' simulationsism. In: Carruthers P, Smith PK, eds. Theories of theories of mind. Cambridge: Cambridge University Press, 11-21.

Goswami, U. (2006) Neuroscience \& Education: From Research to Practice, Nature Reviews Neuroscience 7/5, 406-413.

Guba, E.G. (Ed) (1990) The Alternative Paradigm Dialog, in E.G.Guba (Ed) The Paradigm Dialog, Newbury Park, CA: Sage, 17-27.

Harsh, S. (2013) Towards Methodologically Inclusive Research Syntheses: Expanding Possibilities, London: Routledge.

Head, G. (2003) Effective collaboration: deep collaboration as an essential element of the learning process, Journal of Educational Enquiry, 4/2, 47-62.

Hill, L., Williams, JHG., Aucott, L., Milne, J., Thomson, J., Greig, J., Munro, V. \& MonWilliams, M. (2010). 'Exercising attention within the classroom'. Developmental Medicine and Child Neurology, vol 52, no. 10, pp. 929-934.

Howard-Jones, P. (2007) Neuroscience \& Education: Issues \& Opportunities, London: Teaching and Learning Research Programme (TLRP) University of London.

Howard-Jones, P. (2010) Introducing Neuroeducational Research: Neuroscience, Education and the Brain from Contexts to Practice, Abingdon: Routledge.

Howard-Jone, P. \& Fenton, K.D. (2012) The Need for Interdisciplinary Dialogue in Developing Ethical approaches to Neuroeducational Research, Neuroethics 5, 119-134.

Howard-Jones, P., Holmes, W., Demetriou, S., Jones, C., Tanimoto, E., Morgan, O., Perkins, D. \& Davies, N. (2015) Neuroeducational Research in the Design and Use of a Learning Technology, Learning, Media \& Technology 40/2, 227-246. 
Hyatt, K.J. (2007) Brain Gym: Building Stronger Brains or Wishful Thinking?, Remedial \& Special Education 28/2, 117-124.

Maxwell, S.E. \& Delaney, H.D. (2004) Designing Experiments and Analysing Data, Mahwah, NJ: Lawrence Erlbaum.

Niedenthal PM, Barsalou LW, Winkielman P, Krauth-Gruber S, Ric F. (2006) Embodiment in attitudes, social perception, and emotion. Personality and Social Psychology Review, 9(3):184-211.

OECD (2002) Understanding the Brain: Towards a New Learning Science, Paris, OECD Publications.

Ozonoff S, Cook I, Coon H, (2004) Performance on cambridge neuropsychological test automated battery subtests sensitive to frontal lobe function in people with autistic disorder: Evidence from the collaborative programs of excellence in autism network. Journal of Autism \& Developmental Disorders, 34(2):139-150.

Pellicano E, Dinsmore A and Charman T (2013) A future made together: Shaping autism research in the UK. London:Institute of Education.

Pellicano E, Dinsmore A and Charman T (2014) What should autism research focus upon? Community views and priorities from the United Kingdom, Autism 18(7), 756-770.

Plummer, B.D., Galla, B.M., Finn, A.S., Patrick, S.D., Meketon, D., Leonard, J, Goetz, C., Fernandez-Vina, E., Bartolino, S. White, R.E. \& Duckworth, A.L. (2014) A Behind-TheScenes-Guide to School-Based Research, Mind, Brain \& Education 8/1, 15-20.

Ravet, J. (2015) Supporting Change in Autism Services: Bridging the Gap Between Theory and Practice, London: Sage.

Ravet, J. \& Williams J. (forthcoming) Can imitation skills be taught? A transdisciplinary study of autism and imitation in the secondary classroom.

Samuels, B.M. (2009) Can the Differences Between Education and Neuroscience be Overcome by Mind, Brain and Education? Mind Brain \& Education, 3/1, 45-55.

Saxe R. (2006) Uniquely human social cognition. Current Opinion in Neurobiology, 16(2):235-239.

Scardamalia, M., \& Bereiter, C. (2003) Knowledge building, in J. W. Guthrie (Ed.), Encyclopedia of education (2nd edition), New York: Macmillan USA, 1370-1373.

Schwartz, M. (2015) Mind, Brain \& Education: A Decade of Evolution, Mind, Brain \& Education, 9/2, 64-71.

Sheridan, K., Zinchenko, E. \& Gardner, H. (2006) Neuroethics in Education in Neuroethics: Defining the issues in theory, practice and policy, J. Illes (Ed), Oxford: Oxford University Press. 
Spence, S. (1995) Social Skills Training: Enhancing Social Competence with Children and Adults. London: NFER-Nelson.

Spreng RN, McKinnon MC, Mar RA, Levine B. (2009) The toronto empathy questionnaire: Scale development and initial validation of a factor-analytic solution to multiple empathy measures, Journal of Personality Assessment, 91(1):62-71.

Tashakkori, A. \& Teddlie, C. (Eds) (2003) Handbook of mixed methods in social and behavioural research, Thousand Oaks, CA: Sage.

Varma, S., McCandliss, B.D. \& Schwartz, D.L. (2008) Scientific \& pragmatic challenges for bridging education and neuroscience, Educational Researcher, 37, 140-152.

Wenger, E. (1998): Communities of Practice: learning, meaning and identity, Cambridge, Cambridge University Press

Williams, J. H.G. (2001) Autism, imitation and mirror neurones, Neuroscience and Biobehavioural Reviews 25, 287-295.

Williams, J.H.G., Whiten, A. \& Singh, T. (2004) A systematic review of action imitation in autistic spectrum disorder, Journal of Autism \& Developmental Disorders, 34/3, 285-299.

Williams, J.H.G. (in press) Measuring Imitation Fidelity through Action Evaluation \& Discrimination in Autism to appear in: Frontiers Book edited by Elizabeth B Torres.

Williams, J.H.G. (in press) Measuring Imitation Fidelity through Action Evaluation \& Discrimination in Autism to appear in: Autism: The Movement Sensing Perspective. Eds Elizabeth B. Torres, Caroline Whyatt. Florida, US: CRC Press.

Williams, JHG., Nicolson, ATA., Clephan, KJ., de Grauw, H. \& Perrett, DI. (2013). A novel method testing the ability to imitate composite emotional expressions reveals an association with empathy. PLoS ONE, vol 8, no. 4, e61941. 